\title{
Persistent pre-seismic signature detected by means of Na-K-Mg geothermometry records in a saline spring of Vrancea area (Romania)
}

\author{
H. Mitrofan ${ }^{1}$, C. Marin ${ }^{2}$, D. Zugrăvescu ${ }^{1}$, F. Chitea ${ }^{1,3}$, M.-A. Anghelache ${ }^{1}$, L. Beşuţiu ${ }^{1}$, and A. Tudorache ${ }^{2,4}$ \\ 1 "Sabba Ştefănescu" Institute of Geodynamics of the Romanian Academy, J. L. Calderon str. 19-21, Bucharest, Romania \\ 2"Emil Racoviţă" Institute of Speleology of the Romanian Academy, Calea 13 Septembrie 13, Bucharest, Romania \\ ${ }^{3}$ Faculty of Geology and Geophysics, University of Bucharest, Traian Vuia str. 6, Bucharest, Romania \\ ${ }^{4}$ Faculty of Chemistry, University of Bucharest, Regina Elisabeta str. 2-14, Bucharest, Romania
}

Received: 4 September 2009 - Revised: 25 January 2010 - Accepted: 27 January 2010 - Published: 9 February 2010

\begin{abstract}
A six year-long hydrochemical monitoring operation was conducted in Vrancea seismic zone (Romania), addressing a saline spring that proved to be suitable for Na$\mathrm{K}-\mathrm{Mg}$ geothermometry diagnosis. During the considered time-interval (2003-2009), only one important earthquake $\left(m_{\mathrm{b}}=5.8\right)$ occurred in Vrancea region, this circumstance providing an unambiguous reference-moment between preseismic and post-seismic periods. On occurrence of that earthquake, an anomalous fluctuation of the Na-K temperature was detected - a result largely similar to previous ones recorded worldwide (California, southwest Egypt, northeast India). Yet such fluctuations may not necessarily be induced by earthquake-associated processes: they can occur also "routinely", possibly reflecting some environmental, meteorologically-induced "noise". It was therefore important to examine whether the variations observed in the data values could be plausibly related to a seismogenesis process. By additionally investigating (in a "scattterplot" diagram) the correlation between the Na-K temperatures and the values of a so-called "maturity index", a specific pattern emerged, with pre-seismic data-points plotting in a distinct domain of the diagram; moreover, those data-points appeared to describe a "drift away" pathway with respect to the remaining data-points "cluster", recorded during the subsequent 4 years of post-seismic monitoring. The "drift away" pattern persistently evolved for at least 18 months, ending just before the $m_{\mathrm{b}}=5.8$ earthquake and consequently suggesting the existence of some kind of long-term precursory phenomenon.
\end{abstract}

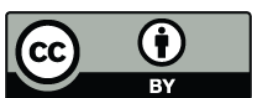

Correspondence to: C. Marin (constmarin@gmail.com)

\section{Introduction}

As hydrothermal solutions flow upward, from large depth toward the earth surface, along with the progressive reduction of their temperature, significant changes occur also in their dissolved-cation content. The slowest rate of chemical adjustment with the host rock is likely to be that of the Na-K cation pair, and therefore the ascending solution would preserve $\mathrm{Na} / \mathrm{K}$ solute ratios which are characteristic to a deep equilibration temperature. That systematic correspondence noticed between the $\mathrm{Na} / \mathrm{K}$ solute ratios of a fluid discharge and the associated groundwater temperatures at depth has been taken into account in devising (Fournier and Truesdell, 1970; Fournier, 1979; Giggenbach, 1988) the Na-K geothermometer investigation method. It calculates values of a socalled Na-K temperature $\left(T_{\mathrm{Na}-\mathrm{K}}\right)$, which is assumed to approximate (Giggenbach, 1988) the actual temperature that exists at the shallowest depth of prolonged stagnation of an ascending groundwater flux.

In certain well discharges of the Cerro-Prieto geothermal field, at the southern end of the San Andreas fault system, Valette-Silver et al. (1985) and Truesdell and Lippmann (1986) have detected episodic increases of the Na-K temperatures by as much as $30^{\circ} \mathrm{C}$ on occurrence of the Imperial Valley earthquake of 15 October $1979\left(m_{\mathrm{b}}=5.7\right)$ and of the Victoria earthquake of 9 June $1980\left(m_{\mathrm{b}}=5.6\right)$. Later on, Idris (2000) noticed that in response to the 12 October 1992 earthquake $\left(m_{\mathrm{b}}=5.9\right)$ recorded in south-western Egypt, there had occurred a $10-18{ }^{\circ} \mathrm{C}$ increase in the Na-K temperatures of certain discharges belonging to the Helwan springs group, several tens of kilometers away from the epicenter. For a saline spring at Slănic Moldova, close to Vrancea seismic

Published by Copernicus Publications on behalf of the European Geosciences Union. 
area, in Romania, Mitrofan et al. (2008) have outlined a fluctuating $T_{\mathrm{Na}-\mathrm{K}}$ episode that had reached a maximum amplitude of about $17^{\circ} \mathrm{C}$ and had lasted for about 18 months before the occurrence of the important $\left(m_{\mathrm{b}}=5.8\right)$ earthquake of 27 October 2004.

In order to account for the connections inferred to exist between the above-indicated earthquakes and the abnormal behaviors of the $T_{\mathrm{Na}-\mathrm{K}}$ parameter, there have been invoked either episodic, seismically-related water-intrusions from deeper (and implicitly hotter) reservoirs (Idris, 2000; Mitrofan et al., 2008), or, occasionally (Valette-Silver et al., 1985), a hypothetical displacement of magma in the vicinity of the sampled aquifer basement. In addition, a correlation between a $\mathrm{Na} / \mathrm{K}$ solute ratio anomaly and a significant $\left(m_{\mathrm{b}}=5.5\right)$ contemporary earthquake has also been documented in northeast India (Skelton et al., 2008); however, the latter authors made no reference to any geothermometryrelated issues, invoking instead variable mixing between two chemically-distinct reservoirs.

Yet in addressing the previously mentioned fluctuations exhibited by the $T_{\mathrm{Na}-\mathrm{K}}$ values on occurrence of significant earthquakes, the indicated papers generally ignored to identify and isolate some environmentally-induced "noise" that could distort the geothermometric "signals" carried by the sampled fluids. Specifically, an ascending hydrothermal solution may also be subject to variable degrees of chemical re-equilibration at shallower depths (lower temperatures), or to the admixture of various amounts of shallow, meteorically-derived waters. All these processes are inferred to induce fluctuations in the $T_{\mathrm{Na}-\mathrm{K}}$ values of a spring discharge (Giggenbach, 1988), even though the corresponding deep-origin temperature (i.e. that at which the fluid had initially been equilibrated) remained the same.

Such "spurious" fluctuations of the $T_{\mathrm{Na}-\mathrm{K}}$ values are expected to occur routinely, without the involvement of any major geo-tectonic events. The original paper of Giggenbach (1988) suggested that variations recorded in the $T_{\mathrm{Na}-\mathrm{K}}$ values of a particular water-discharge should be normally accompanied by some specific evolutions of another parameter, which that author defined as a maturity index (MI). The latter nondimensional parameter estimates - by additionally considering the fast-readjusting $\mathrm{K} / \mathrm{Mg}$ solute ratio - the hydrothermal solution departure from the state of chemical equilibrium mirrored by $T_{\mathrm{Na}-\mathrm{K}}$ : smaller MI values will indicate a more severe chemical disequilibrium, pointing consequently to the fact that the computed $T_{\mathrm{Na}-\mathrm{K}}$ values are less reliable. However, no actual observation data have so far documented, to our knowledge, the inferred $\mathrm{MI}$ versus $T_{\mathrm{Na}-\mathrm{K}}$ correlation patterns.

In the following, in order to isolate the assumed "routine" correlations between $\mathrm{MI}$ and $T_{\mathrm{Na}-\mathrm{K}}$, and to highlight possibly-existing seismotectonically-induced patterns, we have tested the applicability of the "scatterplot" analysis. This rather simple technique has been previously used by Cioni et al. (2007), for identifying earthquake-related signals within time records of certain physical and chemical parameters (temperature, water electrical conductivity, $\mathrm{CO}_{2}$ concentration) of a specific groundwater outlet.

We have processed the chemical-analytical data provided by the hydrochemical monitoring operation that had been conducted since 2003 in Romania, at Slănic Moldova (Mitrofan et al., 2008). The monitored groundwater discharge is situated at the Carpathians arc bend, in close proximity of the highly seismic (Radulian et al., 2000) Vrancea area. The occurrence of one significant $\left(m_{\mathrm{b}}=5.8\right)$ earthquake in that region during the considered monitoring operation has provided an unambiguous reference-moment for clearly distinguishing between pre-seismic and post-seismic periods.

\section{The Na-K-Mg geothermometry approach}

The Na-K-Mg combined geothermometer method was introduced by Giggenbach (1988), mainly as a tool aimed to assess the reliability of the Na-K temperature estimates. While, as previously mentioned, the dissolved cation pair Na-K is likely to respond most slowly to temperature changes undergone by an up-flowing solution, the relative contents of $\mathrm{K}$ and $\mathrm{Mg}$ are, alternatively, much faster to adjust to shallower (and implicitly cooler) thermal conditions. The two subsystems, Na-K and K-Mg, can therefore be viewed as a pair of distinct geothermometers.

For a system that is thoroughly equilibrated in terms of water-rock compositions, the value of the $K-M g$ temperature $\left(T_{\mathrm{K}-\mathrm{Mg}}\right.$ ), computed by means of the K-Mg geothermometer, will match the Na-K temperature value. Alternatively, the two temperatures will progressively depart from each other ( $T_{\mathrm{K}-\mathrm{Mg}}<T_{\mathrm{Na}-\mathrm{K}}$ ), as chemical disequilibrium increasingly affects the cationic composition during the solution upward migration toward the ground surface. A numerical (nondimensional) estimator for that disequilibrium is the "maturity index" (MI), defined by Giggenbach (1988) in terms of the $\mathrm{Na}, \mathrm{K}$ and $\mathrm{Mg}$ concentrations of the ascending hydrothermal solution:

$\mathrm{MI}=0.315 \log \left(c_{\mathrm{K}}^{2} / c_{\mathrm{Mg}}\right)-\log \left(c_{\mathrm{K}} / c_{\mathrm{Na}}\right)$

where the concentrations $c_{\mathrm{Na}}, c_{\mathrm{K}}$ and $c_{\mathrm{Mg}}$ of the ions $\mathrm{Na}^{+}$, $\mathrm{K}^{+}$and respectively $\mathrm{Mg}^{2+}$ are expressed as $\mathrm{mg} / \mathrm{kg}$ (ppm).

When rewriting Eq. (1) in terms of the formulas provided for $T_{\mathrm{Na}-\mathrm{K}}$ and $T_{\mathrm{K}-\mathrm{Mg}}$ by Giggenbach (1988), a rather simple dependence between MI, $T_{\mathrm{Na}-\mathrm{K}}$ and $T_{\mathrm{K}-\mathrm{Mg}}$ becomes apparent:

$\mathrm{MI}=2.66-\left(\frac{1390}{T_{\mathrm{K}-\mathrm{Mg}}+273.16}-\frac{1390}{T_{\mathrm{Na}-\mathrm{K}}+273.16}\right)$

There can be immediately seen from Eq. (2) that under full equilibrium conditions, when $T_{\mathrm{K}-\mathrm{Mg}}=T_{\mathrm{Na}-\mathrm{K}}$, the maturity index reaches its largest value, 2.66. Accordingly, as the values of $T_{\mathrm{K}-\mathrm{Mg}}$ and $T_{\mathrm{Na}-\mathrm{K}}$ progressively depart from each other, MI will gradually decrease below its maximum value 
of 2.66. For several fluid discharges supplied by a common deep hydrothermal reservoir in Taupo Volcanic Zone (New Zealand), Giggenbach (1986) assumed that contrasting departures recorded between the $T_{\mathrm{Na}-\mathrm{K}}$ and $T_{\mathrm{K}-\mathrm{Mg}}$ values likely reflected differences in the rise velocities of the corresponding waters. Therefore MI could be viewed - from an intuitive, yet highly simplified perspective - as a proxy of the time required by a hydrothermal up-flow to reach the sampling point at the surface (specifically, the smaller the MI value, the longer the duration of the fluid up-flow).

A somehow arbitrary value (2.00) has been set by Giggenbach (1988) as the lower MI-threshold below which Na$\mathrm{K}$ temperature assessments were considered to be no more reliable. This value was suggested by empirical observations that concerned samples which were obviously far from chemical equilibrium (such as acid waters or low TDS soda springs), and which systematically ranged in the $\mathrm{MI}<2.0$ domain. Anyway, Giggenbach (1988) stipulated that the $\mathrm{MI}<2.0$ criterion "should only be taken as a rough guideline, as the reliability of the $\mathrm{Na}-\mathrm{K}-\mathrm{Mg}$ geothermometer is likely to decrease gradually with MI, the reliability of $T_{\mathrm{Na}-\mathrm{K}}$ decreasing more rapidly than that of $T_{\mathrm{K}-\mathrm{Mg}}$ ".

There is in addition another limitation which, alternatively, needs to be far more strictly obeyed in diagnosing subsurface fluids by means of the $\mathrm{Na}-\mathrm{K}-\mathrm{Mg}$ geothermometer approach: only near-neutral $\mathrm{pH}$, sodium-chloride or sodiumbicarbonate waters should be considered; in contrast, the method is not applicable in the case of acid sulfate or chloride sulfate water samples.

\section{Vrancea seismic region}

In Vrancea area (Fig. 1), in a narrowly confined subcrustal domain $(20 \mathrm{~km} \times 50 \mathrm{~km}$ lateral extent; $70-180 \mathrm{~km}$ depth range), episodes of intense seismicity occur quite frequently (Radulian et al., 2000; Sperner et al., 2001). The Harvard CMT Catalog ${ }^{1}$ for example has recorded for the 19762009 time interval four distinct episodes when the individual events magnitudes had exceeded $m_{\mathrm{b}}=5.5$, reaching values as high as $m_{\mathrm{b}}=6.7$.

The most recent such instance has occurred on 27 October 2004: the corresponding main event was, by far, the strongest $\left(m_{\mathrm{b}}=5.8\right)$ recorded in Vrancea area since 1990 (Bonjer et al., 2005).

The crustal domain (above $55 \mathrm{~km}$ depth) is, alternatively, subject to only moderate magnitude shocks $\left(m_{\mathrm{b}} \leq 5.0\right)$ : their epicenters are strewn across a much broader area, that essentially overlies the subcrustal seismicity domain, yet also extending farther to the east and to the southeast.

The focal region of the Vrancea subcrustal earthquakes underlies a section of the Eastern Carpathians fold-and-thrust belt which consists of successions of Cretaceous-Neogene

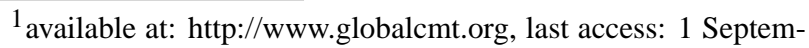
ber 2009
}

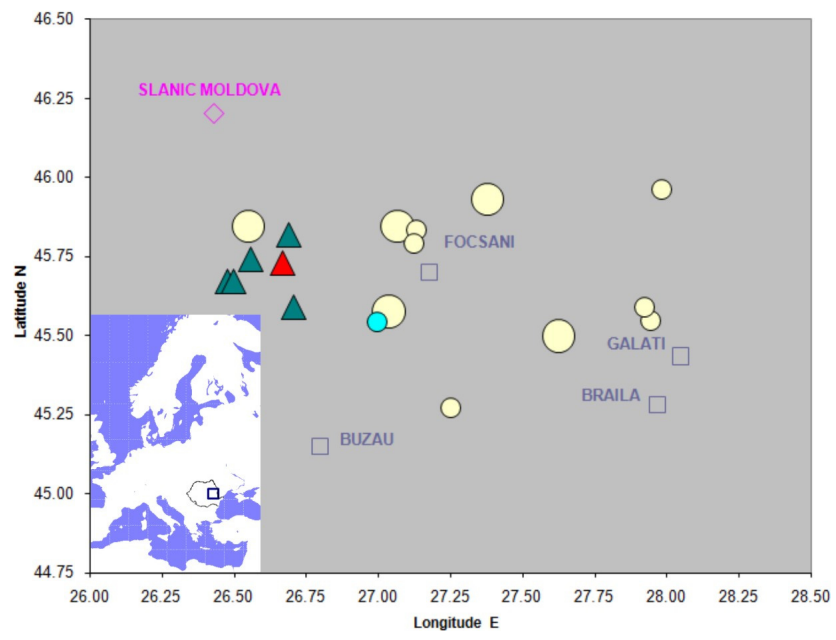

Fig. 1. Location of the sampling site at Slănic Moldova and of the epicenters of the main seismic events recorded in Vrancea area during the hydrochemical monitoring operation. Epicenters of the subcrustal earthquakes listed by the Harvard CMT Catalog ${ }^{1}$ over the considered time-interval (April 2003-May 2009) are indicated by triangles: in red there is represented the important $\left(m_{\mathrm{b}}=5.8\right)$ earthquake of 27 October 2004, while the other subcrustal events $\left(4.8 \leq m_{\mathrm{b}} \leq 5.3\right)$ are represented in dark-green. Dots display the crustal seismicity $\left(m_{\mathrm{b}} \geq 3.0\right)$ recorded by the ISC Catalog ${ }^{2}$ over the same period, with larger symbols designating the $m_{\mathrm{b}} \geq 4.0$ events: in light blue there is indicated the shock having preceded the major earthquake of 27 October 2004, while light-yellow designates shocks having occurred afterwards. Inset map indicates the study area location (rectangle).

flysch deposits. Among the multitude of groundwater outlets sampled by Vaselli et al. (2002) within that thrust belt area, it was only at Slănic Moldova that a considerable amount of mantle-derived ${ }^{3} \mathrm{He}$ could be detected in gas samples, which were associated with discharges of saline fluids. The latter were presumably carried to the surface via deep (regional) faults, an inference additionally supported by the $\mathrm{D}$ and $\mathrm{O}^{18}$ isotopes concentrations and by $\mathrm{Na}-\mathrm{K}-\mathrm{Mg}$ geothermometry diagnoses (Vaselli et al., 2002).

\section{Data acquisition and processing}

At Slănic Moldova, about $30 \mathrm{~km}$ outside the margin of Vrancea epicentral area (Fig. 1), a cold $\left(8.8^{\circ} \mathrm{C}\right.$ average temperature), $\mathrm{H}_{2} \mathrm{~S}$-rich soda-spring that continuously discharged sodium-chloride water has been sampled on an approximately monthly basis between April 2003 and May 2009. The sampling frequency has been occasionally increased, for instance during the 2 months period that followed the important Vrancea earthquake $\left(m_{\mathrm{b}}=5.8\right)$ of 27 October 2004, when there was collected up to 1 sample/day. On the other hand, the time-interval between two consecutive sampling dates has never exceeded 70 days, even in periods when adverse circumstances arose problems of access to the outlet. 
Table 1. Some general characteristics of the hydrochemical monitoring site.

\begin{tabular}{ccccccccc}
\hline $\begin{array}{c}\text { Latitude } \\
\mathrm{N}\end{array}$ & $\begin{array}{c}\text { Longitude } \\
\mathrm{E}\end{array}$ & $\begin{array}{c}\text { Monitoring } \\
\text { time-interval }\end{array}$ & $\begin{array}{c}\text { Outlet } \\
\text { temperature } \\
\text { range }\left({ }^{\circ} \mathrm{C}\right)\end{array}$ & $\begin{array}{c}\mathrm{pH} \\
\text { range }\end{array}$ & $\begin{array}{c}\mathrm{TDS} * \\
\text { range } \\
(\mathrm{g} / \mathrm{kg})\end{array}$ & $\begin{array}{c}T_{\mathrm{Na}-\mathrm{K}} \\
\text { range } \\
\left({ }^{\circ} \mathrm{C}\right)\end{array}$ & $\begin{array}{c}T_{\mathrm{K}-\mathrm{Mg}} \\
\text { range } \\
\left({ }^{\circ} \mathrm{C}\right)\end{array}$ & $\begin{array}{c}\mathrm{MI} \\
\text { range }\end{array}$ \\
\hline 46.20 & 26.43 & 16 April 2003-2 May 2009 & $5.1-13.0$ & $5.60-6.73$ & $10.01-11.53$ & $162-185$ & $123-133$ & $2.26-2.36$ \\
\hline
\end{tabular}

* TDS: total dissolved solids values calculated by summing the major ionic constituents and converting bicarbonate into equivalent carbonate.

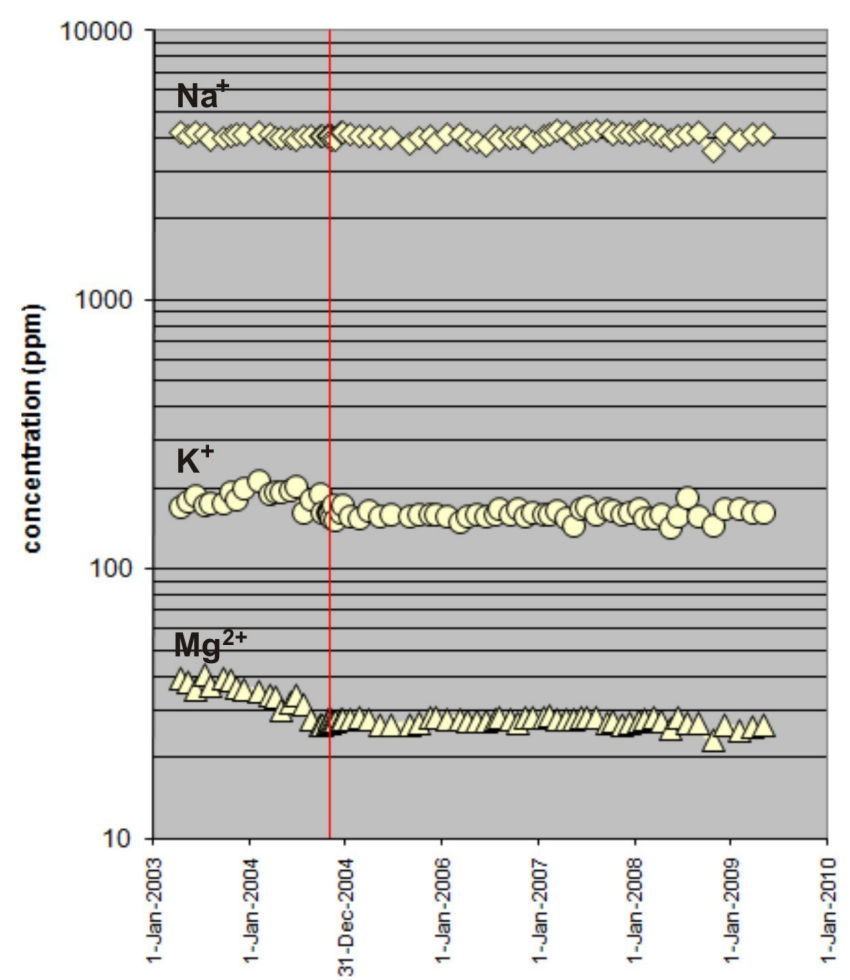

Fig. 2. Time-series of the $\mathrm{Na}^{+}, \mathrm{K}^{+}$and $\mathrm{Mg}^{2+}$ ion concentrations recorded in the monitored spring at Slănic Moldova. The 27 October $2004, m_{\mathrm{b}}=5.8$ earthquake is marked by the red vertical bar.

To a large extent, the present study makes use of the raw chemical data which have already been considered by Mitrofan et al. (2008). The latter authors provided also specific details concerning the analytical methods they had employed.

Additionally, besides updating the Slănic Moldova chemical data-series with more recent samples, our current approach has also included a slight adjustment of the procedure adopted for computing the solution density required in the concentration scales conversion (from $\mathrm{mg} / \mathrm{l}$ to $\mathrm{ppm}$ ): specifically, instead of the formula proposed by Chen and Millero (1986), that had been employed in the paper of Mitrofan et al. (2008), the presently used concentration values have been computed by means of the relations derived by Clegg and Whitfield (1991). The resulting ion concentrations (for which the time series are displayed in Fig. 2) have been further used to compute, by means of procedures defined by Giggenbach (1988), the values of the "Na-K temperature" $\left(T_{\mathrm{Na}-\mathrm{K}}\right)$, of the "K-Mg temperature" $\left(T_{\mathrm{K}-\mathrm{Mg}}\right)$ and of the "maturity index" (MI). The variation-ranges of those parameters, together with other general characteristics of the monitoring site are provided in Table 1.

All the considered samples complied with the basic suitability criteria for the $\mathrm{Na}-\mathrm{K}-\mathrm{Mg}$ geothermometry diagnosis (Giggenbach, 1988), i.e. they had $\mathrm{NaCl}$ chemical character and close-to-neutral $\mathrm{pH}$ values. Additionally, MI values always fell (Table 1) within the 2.00-2.66 range, thus making the considered samples fully compliant with the suitability criteria stipulated by Giggenbach (1988).

For delineating the key-trends in the considered parameters evolutions, the time-series of the actually computed $T_{\mathrm{Na}-\mathrm{K}}, T_{\mathrm{K}-\mathrm{Mg}}$ and $\mathrm{MI}$ values have been filtered by means of a running average procedure (Mitrofan et al., 2008). Specifically, as sampling dates were not evenly distributed in time, the running average of 3 consecutive samples, $\bar{M}_{n}$, was computed by weighting the arithmetic averages of each two consecutive samples, $\left(M_{n}+M_{n-1}\right) / 2$ and $\left(M_{n}+M_{n+1}\right) / 2$ respectively, with the reverse of the time interval between the corresponding sampling dates $\left(1 /\left(t_{n}-t_{n-1}\right)\right.$, and $1 /\left(t_{n+1}-\right.$ $\left.t_{n}\right)$, respectively). The overall corresponding expression reads:

$\bar{M}_{n}=\frac{\frac{1}{2} \sum_{k=n}^{n+1} \frac{M_{k-1}+M_{k}}{t_{k}-t_{k-1}}}{\sum_{k=n}^{n+1} \frac{1}{t_{k}-t_{k-1}}}$

where $M$ stands for either $T_{\mathrm{Na}-\mathrm{K}}, T_{\mathrm{K}-\mathrm{Mg}}$ or $\mathrm{MI}$, as appropriate.

Additionally, residuals $\left(M_{n}-\bar{M}_{n}\right)$ have been computed for all three above-indicated parameters and plotted in Fig. 3. We estimate that the computed residuals incorporate both irregular hydrological inputs, and random errors which affected the chemical-analytical procedures. Unfortunately, uncertainties associated with the use of the $\mathrm{Na}-\mathrm{K}-\mathrm{Mg}$ geothermometer equations are not specified in Giggenbach (1988). This is in contrast with more recent approaches (for instance Díaz-González and Santoyo, 2008; Díaz-González 
Table 2. Main seismic events having occurred in Vrancea area during the hydrochemical monitoring operation (April 2003-May 2009). The strongest earthquakes (as recorded by the Harvard CMT Catalog ${ }^{1}$ ) are all located in the subcrustal domain (the italic font entries). In addition there are listed (in normal font) the significant $\left(m_{\mathrm{b}} \geq 3.0\right)$ crustal earthquakes, as indicated by the ISC Catalog ${ }^{2}$. The entry for the major event of 27 October 2004 is listed in bold text.

\begin{tabular}{rllrccc}
\hline \multicolumn{1}{c}{ Date } & $\begin{array}{c}\text { Latitude } \\
\mathrm{N}\end{array}$ & $\begin{array}{c}\text { Longitude } \\
\mathrm{E}\end{array}$ & $\begin{array}{c}\text { Depth } \\
(\mathrm{km})\end{array}$ & $\begin{array}{c}\text { Depth } \\
\text { domain }\end{array}$ & $\begin{array}{c}\text { Magnitude } \\
\left(m_{\mathrm{b}}\right)\end{array}$ & Catalog \\
\hline 30 April 2004 & 45.5445 & 26.9950 & 37.0 & crustal & 3.9 & ISC \\
27 September 2004 & 45.74 & 26.56 & 153.5 & subcrustal & 4.8 & Harvard CMT \\
27 October 2004 & $\mathbf{4 5 . 7 3}$ & $\mathbf{2 6 . 6 7}$ & $\mathbf{9 3 . 8}$ & subcrustal & $\mathbf{5 . 8}$ & Harvard CMT \\
17 December 2004 & 45.9330 & 27.3776 & 0.9 & crustal & 4.0 & ISC \\
14 May 2005 & 45.67 & 26.48 & 139.0 & subcrustal & 5.1 & Harvard CMT \\
18 June 2005 & 45.67 & 26.50 & 138.4 & subcrustal & 4.8 & Harvard CMT \\
21 August 2005 & 45.5474 & 27.9472 & 4.2 & crustal & 3.2 & ISC \\
21 August 2005 & 45.5915 & 27.9259 & 3.0 & crustal & 3.5 & ISC \\
10 September 2005 & 45.2709 & 27.2521 & 33.0 & crustal & 3.6 & ISC \\
31 October 2005 & 45.8329 & 27.1341 & 53.9 & crustal & 3.7 & ISC \\
15 November 2005 & 45.8480 & 27.0691 & 54.0 & crustal & 4.5 & ISC \\
13 December 2005 & 45.82 & 26.69 & 138.3 & subcrustal & 4.8 & Harvard CMT \\
30 January 2006 & 45.9623 & 27.9815 & 18.2 & crustal & 3.5 & ISC \\
30 October 2007 & 45.4970 & 27.6250 & 50.0 & crustal & 4.1 & ISC \\
29 November 2007 & 45.5740 & 27.0400 & 7.1 & crustal & 4.0 & ISC \\
21 March 2008 & 45.7900 & 27.1250 & 23.0 & crustal & 3.7 & ISC \\
6 September 2008 & 45.8480 & 26.5490 & 24.6 & crustal & 4.5 & ISC \\
25 April 2009 & 45.59 & 26.71 & 106.6 & subcrustal & 5.3 & Harvard CMT \\
\hline
\end{tabular}

et al., 2008), which in proposing novel $\mathrm{Na}-\mathrm{K}$ temperature equations, also indicated the uncertainties associated to each of the equation coefficients. We still preferred to use in the present study - in spite of an inevitably smaller accuracy of the error assessments - the original equations of Giggenbach's Na-K-Mg geothermometer: the reason was that none of the subsequent refinements of the considered ionic geothermometers provided a similarly integrated set of numerical relationships.

For the three parameters $\left(T_{\mathrm{Na}-\mathrm{K}}, T_{\mathrm{K}-\mathrm{Mg}}\right.$ and $\left.\mathrm{MI}\right)$ derived by means of the $\mathrm{Na}-\mathrm{K}-\mathrm{Mg}$ combined geothermometer method, the time series of the averaged values, processed as aboveindicated, are plotted in Fig. 4. A preliminary visual inspection can thus be made of the actually recorded behavior, as compared to the one predicted by Eq. (2): specifically, one may evaluate how MI fluctuations are correlated with those of $T_{\mathrm{Na}-\mathrm{K}}$ and of $T_{\mathrm{K}-\mathrm{Mg}}$.

There can be noticed (Fig. 4a) that the averaged time series of $\mathrm{MI}$ and of $T_{\mathrm{Na}-\mathrm{K}}$ display contrary, yet highly coherent evolutions. This circumstance is also substantiated by the very good coefficient obtained for the direct correlation between $\mathrm{MI}$ and $T_{\mathrm{Na}-\mathrm{K}}(R=-0.91)$. Alternatively, variations displayed by $T_{\mathrm{K}-\mathrm{Mg}}$ appear to be much less significant (Fig. $4 \mathrm{~b})$ and virtually uncorrelated with those of $\mathrm{MI}(R=-0.21$ for the MI versus $T_{\mathrm{K}-\mathrm{Mg}}$ correlation).
The overall setting suggested by Fig. 4 is that in the case of the considered spring discharge, the $T_{\mathrm{K}-\mathrm{Mg}}$ - dependent term in Eq. (2) behaves more or less like a constant. Under this particular circumstance, the relationship expressed by Eq. (2) is reduced, to a large extent, to a reverse correlation between MI versus $T_{\mathrm{Na}-\mathrm{K}}-\mathrm{a}$ fact which Fig. $4 \mathrm{a}$ indeed seems to suggest.

The next step has been to construct a scatterplot diagram, in which there were plotted the averaged values of MI versus the averaged values of $T_{\mathrm{Na}-\mathrm{K}}$ (Fig. 5). That latter procedure - somehow analogous to one previously used by Cioni et al. (2007) for identifying earthquake-related signals in time-series of temperature, electrical conductivity and $\mathrm{CO}_{2}$ concentration of a specific outlet - made readily apparent certain distinct correlation-regimes, which shall be given detailed discussion in the next section.

In order to test the ionic geothermometry approach sensitivity to nearby significant earthquakes, there have been in the first place considered all the seismic events that the Harvard CMT Catalog ${ }^{1}$ listed for Vrancea area over the concerned monitoring period (Table 2).

There can be noticed (Table 2) that during the considered period, no crustal earthquake was strong enough for being recorded by the Harvard CMT Catalog ${ }^{1}$. Nevertheless, even moderate-magnitude crustal earthquakes might have possibly been associated to geothermometric anomalies, which had been inferred to originate (Mitrofan et al., 2008) no deeper 

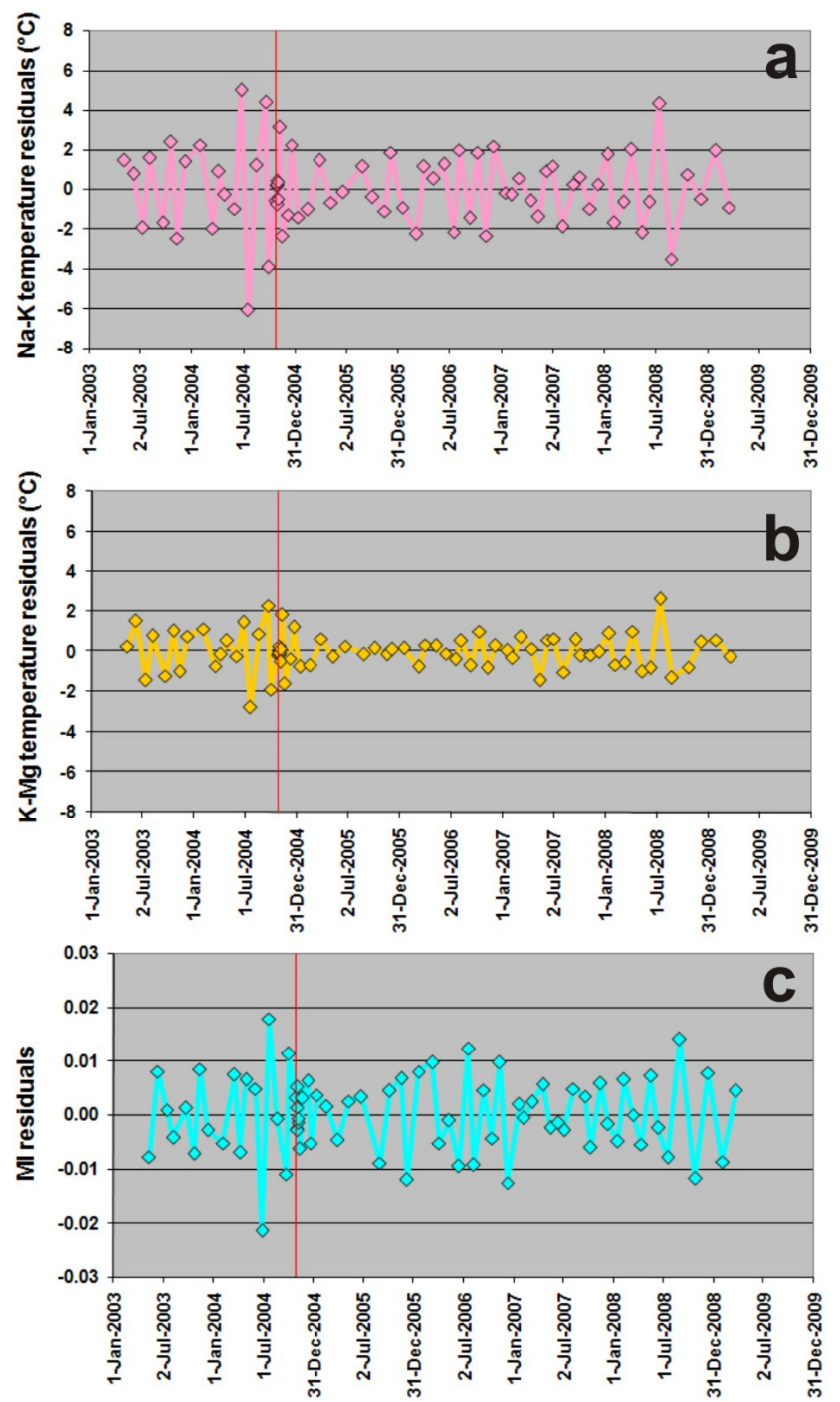

Fig. 3. Residuals (differences between the values actually computed and the averaged values), illustrated as time-series for: (a) $T_{\mathrm{Na}-\mathrm{K}}$; (b) $T_{\mathrm{K}-\mathrm{Mg}}$; (c) MI. The 27 October 2004, $m_{\mathrm{b}}=5.8$ earthquake is marked by the red vertical bar.

than $7-8 \mathrm{~km}$. That is why our analysis has also considered (Table 2) the main crustal events $\left(m_{\mathrm{b}} \geq 3.0\right)$, listed for Vrancea area by the ISC Catalog 2 . From that catalog, we have generally retrieved the ISC reviewed data; yet for the earthquakes having occurred since August 2007 - for which ISC data-revisions were no more available - we have retrieved instead, from the same catalog, the data provided by the National Earthquake Information Center (NEIC) of the US Geological Survey.

\footnotetext{
2available at: http://www.isc.ac.uk/search/bulletin, last access: 1 September 2009
}
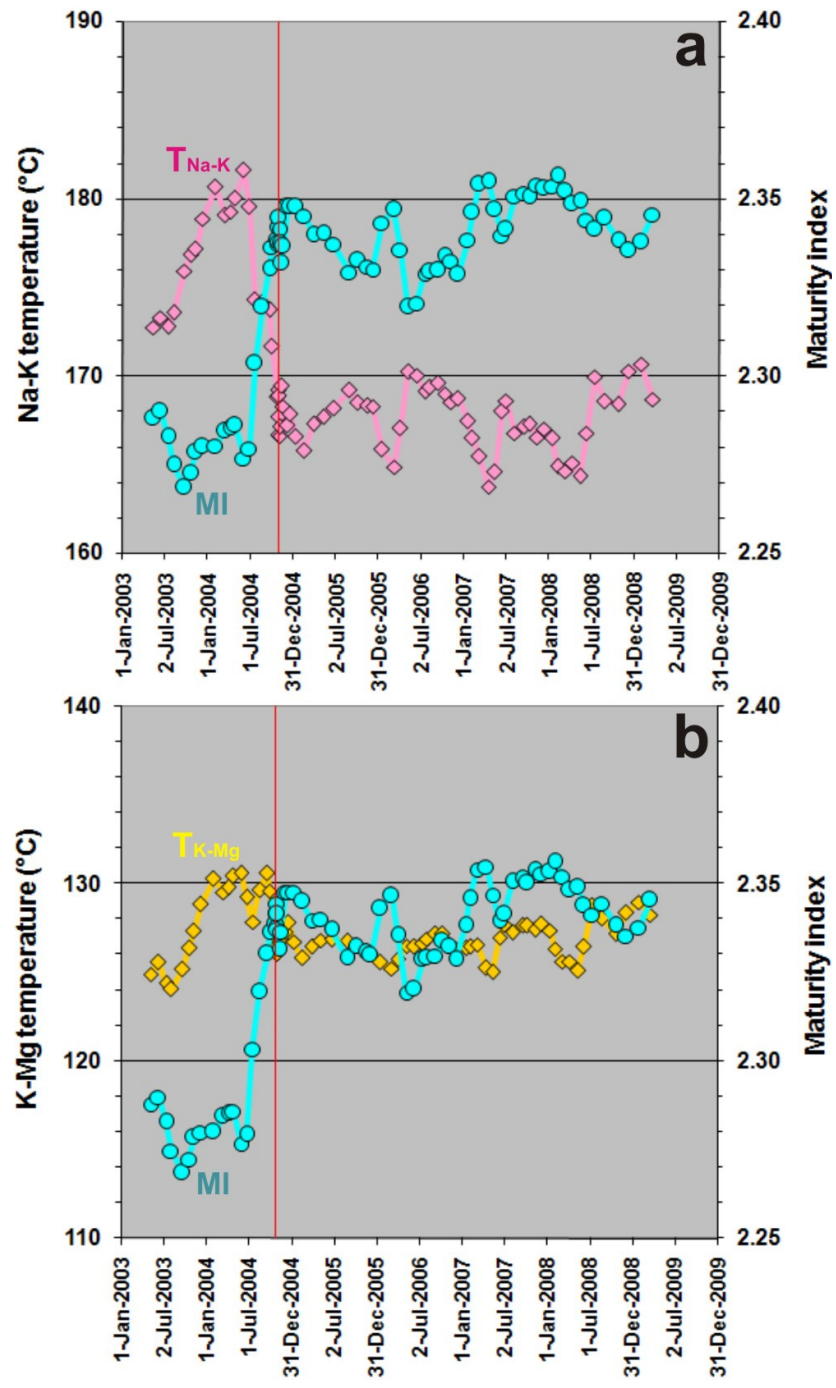

Fig. 4. Comparative illustrations of the averaged time-series of: (a) MI and $T_{\mathrm{Na}-\mathrm{K}}$; (b) MI and $T_{\mathrm{K}-\mathrm{Mg}}$. The 27 October $2004, m_{\mathrm{b}}=5.8$ earthquake is marked by the red vertical bar.

\section{Results and discussion}

On the MI versus $T_{\mathrm{Na}-\mathrm{K}}$ scatterplot (Fig. 5) two distinct correlation-regimes are noticeable:

- highly correlated data-points, occurring as some kind of "cluster";

- a series of more poorly correlated data-points, which appear to "drift away" from the main "cluster".

\subsection{The "drift away" regime}

The "drift away" data-points correspond to sampling dates which cover the time-interval from the very beginning of the monitoring operation (the first averaged-values are ascribed to 10 May 2003), until October 2004: averaged 
values ascribed to 30 September 2004 still belong to the "drift away" domain, while the subsequent sampling date, 26 October 2004, provides the first data-point which already "reaches" into the cluster.

The next sampling date was 29 October 2004 which, similarly to all subsequent sampling dates, belonged to the "cluster" domain. In-between the two consecutive sampling dates of 26 October 2004 and of 29 October 2004, there has occurred the strongest Vrancea earthquake recorded during that monitoring operation ( 27 October $2004, m_{\mathrm{b}}=5.8$ ).

It clearly results that the entire "drift" period predated that important seismic event, ending shortly before its occurrence (Fig. 5). On the other hand, no other "drift" regime was recorded on occurrence of the subsequent, lower magnitude events indicated in Table 2 and Fig. 6.

Those observations seem to indicate that the "drift" regime was generated under certain exceptional circumstances and that its occurrence could have been associated with the strongest Vrancea seismic event recorded during the monitoring period.

Additionally, a knick-point (actually preceded also by some kind of "loop" behavior) was discernible in the "drift" regime (Fig. 5): it marked the moment from which on data points started to "drift back" toward the main "cluster". It is interesting to notice (Fig. 5) that the knick-point occurrence was roughly contemporary to the only significant crustal earthquake (in fact, the main shock of an earthquake sequence - Radulian et al., 2007) recorded in Vrancea region during the "drift away" period (Figs. 1 and 6).

The indicated overall setting suggests that the "drift" behavior exhibited certain specific patterns, both on occurrence of a Vrancea major subcrustal earthquake, and on occurrence of the most significant crustal event preceding it. Since the immediate cause of the processes controlling the observed Na-K-Mg geothermometer fluctuations assumedly occurred in the shallow crust, at a depth of about $7-8 \mathrm{~km}$ at maximum (Mitrofan et al., 2008), a definite coupling should then exist between subcrustal and crustal deformations, related - in one way or another - to the generation of the Vrancea major earthquakes. This is in contrast with opinions expressed by most previous investigators, who, by taking into account the overall Vrancea seismicity pattern, appeared to be reticent in admitting that present-day deformation of the crust could be distinctively related to the subcrustal domain seismogenesis (see, for instance, Sperner et al., 2001; Gvirtzman, 2002; Van Der Hoeven et al., 2005; Heidbach et al., 2007; Radulian et al., 2007; Caporali et al., 2008).

\subsection{The "cluster" regime}

As compared to those of the "drift" regime, the "cluster" domain data points occur more tightly correlated, within a narrower, more compact region of the diagram. There is a visible distinction between "cluster" and "drift" data-points also in terms of quality of their corresponding MI versus $T_{\mathrm{Na}-\mathrm{K}}$

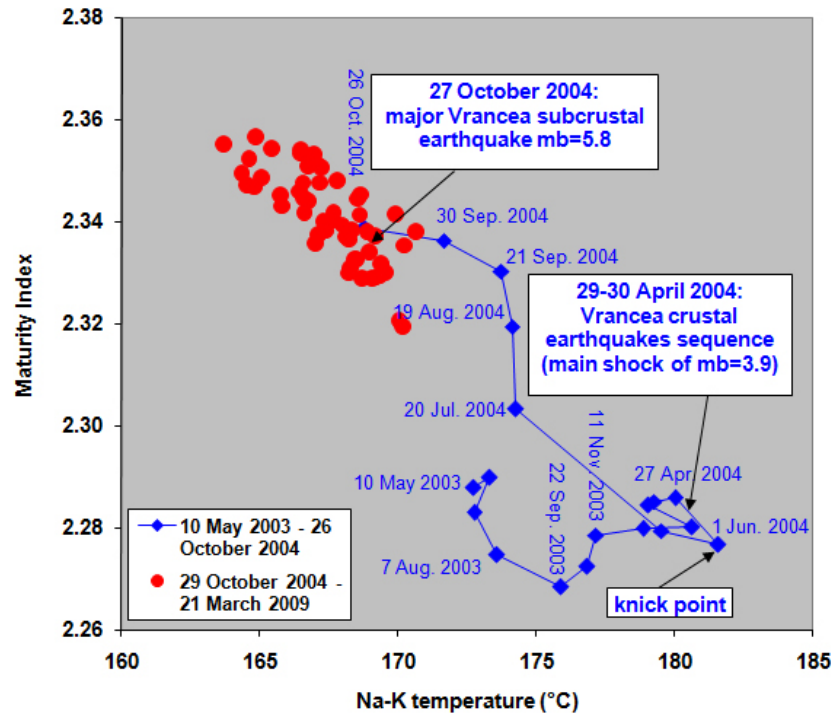

Fig. 5. MI vs. $T_{\mathrm{Na}-\mathrm{K}}$ scatterplot (plotted values had been averaged as indicated in the text). The red dots "cluster" is interpreted to reflect "routine" behavior (i.e. occurring in the absence of major geotectonic events). The blue diamonds indicate an anomalous ("drift") behavior (occurred during the time-span May 2003-October 2004), assumedly associated to the strong $\left(m_{\mathrm{b}}=5.8\right)$ subcrustal earthquake of 27 October 2004. Selected sampling dates during the "drift" event are indicated by blue labels. Notice that close to the "drift" regime knick-point (marking the moment when data points started to "drift back" toward the main "cluster"), there has occurred the only significant crustal earthquake (in fact, the main shock of an earthquake sequence - Radulian et al., 2007) recorded in Vrancea region during the "drift away" period.

correlations: $R=-0.76$ for the "cluster" regime, as compared to $R=-0.53$ for the "drift" regime.

Relying on the above considerations, we presume that the "cluster" regime is the expression of inter-relationships which Giggenbach (1988) inferred to exist between $T_{\mathrm{Na}-\mathrm{K}}$ and MI values of a specific groundwater discharge "routinely", i.e. in the absence of any disturbing processes (major geo-tectonic events included). Specifically, there seems that none of the many moderate-magnitude earthquakes that occurred in Vrancea area after October 2004 - either in the subcrustal or the crustal domains (Figs. 1 and 6) - correspondingly acted as a "disturbing process".

\section{Conclusions}

According to previous investigations, ionic (Na-K-Mg) geothermometers might be able to diagnose episodic, earthquake-related alterations in the overall thermohydrological regime of a deep-origin groundwater discharge. Yet some specific, robust procedure was still necessary for discriminating between genuine seismically-related signatures, and certain "spurious" fluctuations of the 

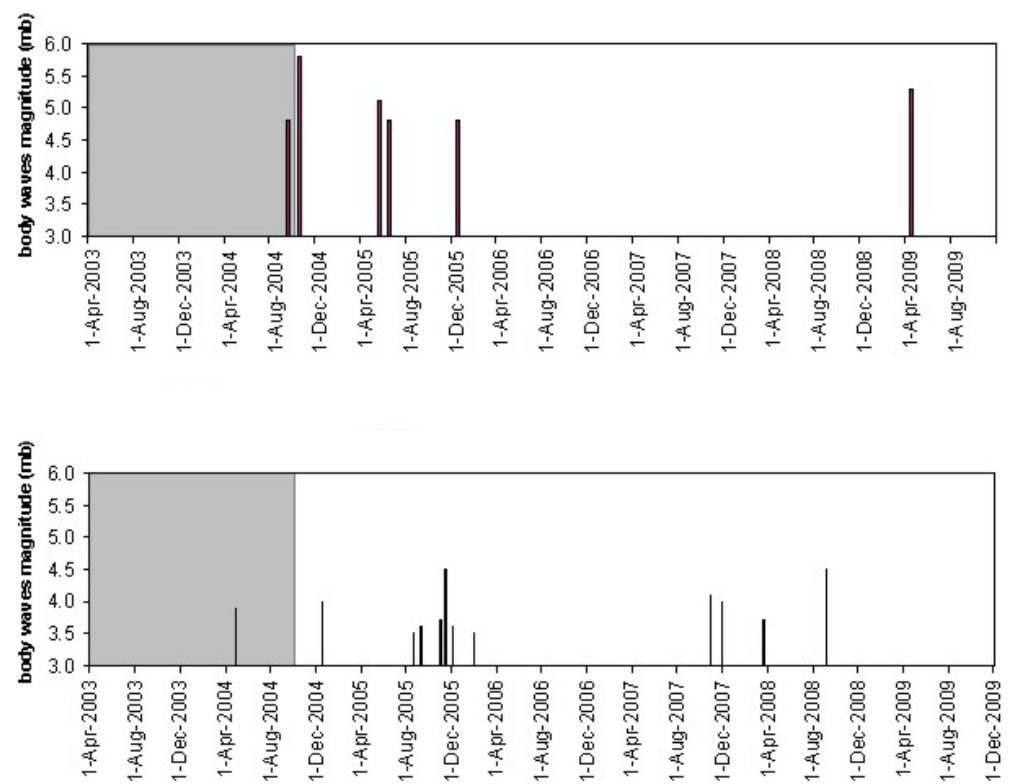

Fig. 6. Time-series of the significant seismic events recorded in Vrancea area during the hydrochemical monitoring operation. Above: the strongest earthquakes of that period, as indicated by the Harvard CMT Catalog ${ }^{1}$ (all those events have occurred in the subcrustal domain); below: ISC Catalog ${ }^{2}$ records of the significant crustal events which, however, due to their moderate magnitudes $\left(3.0 \leq m_{\mathrm{b}} \leq 4.5\right)$, had not been included in the Harvard CMT Catalog 1 . The shaded region indicates the period when the "drift" regime has occurred.

geothermometrically-derived temperatures. In an attempt to fulfil this requirement, we processed, by means of the scatterplot diagrams approach, the chemical-analytical data provided by a monitoring operation that had addressed a saline spring at Slănic Moldova, close to Vrancea seismic area.

For that specific spring discharge, the Na-K temperature $\left(T_{\mathrm{Na}-\mathrm{K}}\right)$ fluctuations seem to be strongly correlated with those of the "maturity index" (MI), a parameter which quantifies (Giggenbach, 1988) the extent to which the chemical composition of a sampled fluid departs from the last attained water-rock "full-equilibrium" conditions. The particular circumstance of an outstandingly good correlation between MI and $T_{\mathrm{Na}-\mathrm{K}}$ appears to be associated with rather insignificant fluctuations undergone by the $\mathrm{K}-\mathrm{Mg}$ temperature $\left(T_{\mathrm{K}-\mathrm{Mg}}\right)$. There aren't so far available any other data, derived from distinct monitored discharges, which could indicate whether such type of relationships between MI, $T_{\mathrm{Na}-\mathrm{K}}$ and $T_{\mathrm{K}-\mathrm{Mg}}$ are of widespread occurrence, or if they just reflect certain local characteristics.

By further plotting MI against the $T_{\mathrm{Na}-\mathrm{K}}$ values for the Slănic Moldova spring, two distinct regimes became noticeable: one consisting of highly correlated data-points, occurring as a dense "cluster", and the other one including a series of more poorly correlated data-points, which appeared to "drift away" from the main "cluster". The "cluster" regime persisted during the entire period (in excess of 4 years) that followed the strongest Vrancea earthquake (27 October 2004, $m_{\mathrm{b}}=5$.8) recorded during the monitoring ope- ration. Alternatively, that seismic event had been predated by a continuous, 18-months-long "drift" period; the "drift" phenomenon ended just before the strong earthquake, and no other "drift" regimes were observed on occurrence of the lower magnitude events recorded subsequently.

Those observations seem to indicate that while the "cluster" regime mirrored the "routine" behavior of a deep origin groundwater discharge, the "drift" regime has occurred under certain exceptional circumstances: the latter were most probably connected to the preparation stage of the strongest Vrancea earthquake recorded during the monitoring operation.

Acknowledgements. We feel deeply indebted to Manfred Hochstein for his keen interest in our investigations and for his valuable comments and suggestions. We also express our gratitude toward Nathlie J. Valette-Silver and toward late Paul G. Silver, who several decades after pioneering the domain of the seismicallyrelated anomalies recorded by ionic geothermometers, have also provided a kind support to our research. For their dedicated assistance in the field activities we are grateful to Cristina Călugăreanu, Dorel Cojocaru, Virgil Drăguşin, Mihaela Ghiţă, Paul Horvath, Marcel Oancea, Iulian Popa, Marian Popescu, and especially to Mihaela and Ion Radu. We also acknowledge the efforts of Floarea Răducă, who greatly contributed in the performed laboratory work. In addition, we thank the three anonymous referees whose useful suggestions greatly improved our manuscript. The Romanian Authority for Scientific Research has partly funded this research through the CEEX-MENER 732/2006 and CNMP 32$112 / 2008$ grants. 
Edited by: M. E. Contadakis

Reviewed by: three anonymous referees

\section{References}

Bonjer, K.-P., Ionescu, C., Sokolov, V., Radulian, M., Grecu, B., Popa, M., and Popescu, E.: Source parameters and ground motion pattern of the 27 October 2004 intermediate depth Vrancea earthquake, in: EGU General Assembly, Vienna, Austria, 24-29 April 2005, EGU05-A-07538, 2005.

Caporali, A., Aichhorn, C., Becker, M., Fejes, I., Gerhatova, L., Ghitau, D., Grenerczy, G., Hefty, J., Krauss, S., Medak, D., Milev, G., Mojzes, M., Mulic, M., Nardo, A., Pesec, P., Rus, T., Simek, J., Sledzinski, J., Solaric, M., Stangl, G., Vespe, F., Virag, G., Vodopivec, F., and Zablotskyi, F.: Geokinematics of Central Europe: New insights from the CERGOP-2/Environment Project, J. Geodyn., 45, 246-256, 2008.

Chen, C.-T. A. and Millero, F. J.: Precise thermodynamic properties for natural waters covering only the limnological range, Limnol. Oceanogr., 31, 657-662, 1986.

Cioni, R., Guidi, M., Pierotti, L., and Scozzari, A.: An automatic monitoring network installed in Tuscany (Italy) for studying possible geochemical precursory phenomena, Nat. Hazards Earth Syst. Sci., 7, 405-416, 2007, http://www.nat-hazards-earth-syst-sci.net/7/405/2007/.

Clegg, S. L. and Whitfield, M.: Activity coefficients in natural waters, in: Activity Coefficients in Electrolyte Solutions, edited by: Pitzer, K. S., CRC Press, Inc., Boca Raton, Florida, Ch. 6, 279 434, 1991

Díaz-González, L. and Santoyo, E.: A new precise calibration of the $\mathrm{Na} / \mathrm{K}$ geothermometer using a world database of geothermal fluids and improved geochemometric techniques, Geochim. Cosmochim. Ac., 72, (12 Supplement 1), A215, 2008.

Díaz-González, L., Santoyo, E., and Reyes-Reyes, J.: Three new improved $\mathrm{Na} / \mathrm{K}$ geothermometers using computational and geochemiometrical tools: Application to the temperature prediction of geothermal systems (in Spanish), Rev. Mex. Cienc. Geol., 25, 465-482, 2008.

Fournier, R. O.: A revised equation for the $\mathrm{Na} / \mathrm{K}$ geothermometer, Geothermal Resources Council Transactions, 3, 221-224, 1979.

Fournier, R. O. and Truesdell, A. H.: Chemical indicators of subsurface temperature applied to hot spring waters of Yellowstone National Park, Wyoming, U.S.A, in: Proceedings of the U.N. Symposium on the Development and Utilization of Geothermal Resources, Pisa, Italy, 22 September-1 October 1970 (Geothermics, Special Issue 2), 2 (Part I), 529-535, 1970.

Giggenbach, W. F.: Graphical techniques for the evaluation of the of water/rock equilibration conditions by use of $\mathrm{Na}, \mathrm{K}, \mathrm{Mg}$ and $\mathrm{Ca}$ - contents of discharge waters, in: Proceedings of the 8th New Zealand Geothermal Workshop, Auckland, New Zealand, 37-42, November 1986.

Giggenbach, W. F.: Geothermal solute equilibria. Derivation of NaK-Mg-Ca geoindicators, Geochim. Cosmochim. Ac., 52, 27492765,1988
Gvirtzman, Z.: Partial detachment of a lithospheric root under the southeast Carpathians: Toward a better definition of the detachment concept, Geology, 30, 51-54, 2002.

Heidbach, O., Ledermann, P., Kurfeß, D., Peters, G., Buchmann, T., Matenco, L., Negut, M., Sperner, B., Müller, B., Nuckelt, A., and Schmitt, G.: Attached or not attached: slab dynamics beneath Vrancea, Romania, in: Proceedings of the International Symposium on Strong Vrancea Earthquakes and Risk Mitigation, Bucharest, Romania, 4-6 October 2007, 3-20, 2007.

Idris, M.: Geothermal evaluation for thermal fluids of Helwan springs Egypt, in: Proceedings of the World Geothermal Congress 2000, Kyushu-Tohoku, Japan, 1295-1299, 28 May-10 June 2000.

Mitrofan, H., Marin, C., Zugrăvescu, D., Tudorache, A., Beşuţiu, L., and Radu, M.: Transients of Giggenbach's 'Na-K-Mg-Ca Geoindicators' preceding the 27 October 2004, $\mathrm{M}_{w}=6.0$ earthquake in Vrancea area (Romania), Terra Nova, 20, 87-94, 2008.

Radulian, M., Bonjer, K.-P., Popa, M., and Popescu, E.: Seismicity patterns in SE Carpathians at crustal and subcrustal domains: tectonic and geodynamic implications, in: Proceedings of the International Symposium on Strong Vrancea Earthquakes and Risk Mitigation, Bucharest, Romania, 4-6 October 2007, 93102, 2007.

Radulian, M., Mândrescu, N., Panza, G. F., Popescu, E., and Utale, A.: Characterization of seismogenic zones of Romania, Pure Appl. Geophys., 157, 55-77, 2000.

Skelton, A., Claesson, L., Chakrapani, G., Mahanta, C., Routh, J., Mörth, M., and Khanna, P.: Coupling between seismic activity and hydrogeochemistry at the Shillong Plateau, Northeastern India, Pure Appl. Geophys., 165, 45-61, 2008.

Sperner, B., Lorenz, F. P., Bonjer, K.-P., Hettel, S., Müller, B., and Wenzel, F.: Slab break-off - abrupt cut or gradual detachment? New insights from the Vrancea Region (SE Carpathians, Romania), Terra Nova, 13, 172-179, 2001.

Truesdell, A. H. and Lippmann, M. J.: The lack of immediate effects from the 1979-80 Imperial and Victoria earthquakes on the exploited Cerro Prieto geothermal reservoir, Geothermal Resources Council Transactions, 10, 405-411, 1986.

Valette-Silver, N. J., Silver, P. G., and Marquez, M. R.: The effect of a tectonic disturbance on the Cerro Prieto geothermal field (B.C., Mexico), Geothermal Resources Council Transactions, 9(Part I), 515-520, 1985.

Van Der Hoeven, A. G. A., Mocanu, V., Spakman, W., Nutto, M., Nuckelt, A., Matenco, L., Munteanu, L., Marcu, C., and Ambrosius, B. A. C.: Observation of present-day tectonic motions in the Southeastern Carpathians: results of the ISES/CRC-461 GPS measurements, Earth Planet. Sc. Lett., 239, 177-184, 2005.

Vaselli, O., Minissale, A., Tassi, F., Magro, G., Seghedi, I., Ioane, D., and Szakacs, A.: A geochemical traverse across the Eastern Carpathians (Romania): constraints on the origin and evolution of the mineral water and gas discharges, Chem. Geol., 182, 637654,2002 